\title{
IMPLEMENTASI PETA DIGITAL UNTUK SMART VILLAGE (STUDI KASUS DESA TAMMANGALLE, POLEWALI MANDAR)
}

\author{
Masrianto $^{1,}$ Harianto $^{2}$, Ashabul Kahfi ${ }^{3}$, Muhammad Sarjan ${ }^{4}$ \\ ${ }^{1234}$ Program Studi Sistem Informasi \\ Universitas AL Asyariah Mandar \\ masriantobiawak@gmail.com ${ }^{1}$, muhsarjan2018@gmail.com²
}

\begin{abstract}
ABSTRAK
Organisasi, perusahaan, maupun lembaga-lembaga pemerintah yang bergerak dalam bidang yang berhubungan dengan objek-objek memberikan informasi posisi sistem dengan memanfaatkan Teknologi Informasi (IT) yang berbasiskan web. Teknologi tersebut memiliki fitur Sistem Informasi Geografis (SIG) yang dirancang untuk memenuhi kebutuhan tersebut. Aplikasi-aplikasi seperti GIS on Web, peta digital pada Sistem Informasi misalnya untuk menunjukkan posisi objek berupa informasi letak objek yang ada di desa Tammangalle. Aplikasi penggunaan Peta Digital ini merupakan aplikasi yang umum digunakan dari teknologi Geographic Information Sytem (GIS) atau Sistem Informasi Geografis (SIG). GIS akan menampilkan data secara real time atau menampilkan kembali (playback) data - data yang lalu yang akan diberi simbol dan warna tertentu berdasarkan atribut, waktu dan posisinya. GIS merupakan sistem yang berbasis website untuk memproses, menyusun, memanipulasi, dan menyajikan data spasial (data bergeoreferensi) atau data geografik yang berhubungan dengan semua persoalan \& keadaan serta fenomena yang ada di dunia nyata (real world) yang sangat dibutuhkan dalam petunjuk serta monitoring suatu objek di bumi.
\end{abstract}

Kata kunci: Desa Tammangalle, Peta Digital, GIS, Web

\begin{abstract}
Organizations, companies, and government institutions engaged in objects related to providing information on the position of the system by utilizing web-based Information Technology (IT). The technology has a Geographic Information System (GIS) feature designed to meet these needs. Applications such as GIS on Web, digital maps on Information Systems for example to show the position of objects in the form of information on the location of objects in the village of Tammangalle. This application uses Digital Maps is an application that is commonly used from Geographic Information System technology (GIS) or Geographic Information Systems (GIS). GIS will display data in real time or replay (playback) of past data which will be given certain symbols and colors based on attributes, time and position. GIS is a website-based system for processing, compiling, manipulating, and presenting spatial data (georeferenced data) or geographic data relating to all problems \& conditions and phenomena in the real world that are really needed in the instructions and monitoring an object on earth.
\end{abstract}

Keywords: Tammangalle Village, Digital Map, GIS, Web 


\section{PENDAHULUAN}

Sistem Kecepatan dalam mendapatkan informasi adalah kunci dalam mendapatkan kesuksesan dan keberhasilan [1]. Penggunaan teknologi informasi sebagai mendia informasi kini dibutuhkan disemua lini untuk kepentingan peningkatan daya saing dan promosi, utamanya promosi kawasan atau objek wisata, termasuk promosi desa wisata. Desa Tamangalle yang terletak di Kecamatan Balanipa Kabupaten Polewali Mandar Provinsi Sulawesi barat dikenal sebagai salah satu kawasan yang sangat memiliki banyak objek pariwisata. Melihat dari potensipotensi desa, perencanaan pembangunan desa sangatlah diperlukan untuk menjamin antara perkembangan teknologi dengan potensi desa untuk lebih memudahkan masyarakat luar maupun setempat dalam aktivitasnya untuk mencari informasi lebih cepat dengan menggunakan teknologi informasi berbasis web [2]. Perkembangan teknologi informasi yang banyak membantu dalam melakukan promosi adalah teknologi website serta mampu menjadi media komunikasi [3] website dapat digunakan untuk menyampaikan informasi terbaru dalam berbagai bidang untuk setiap kegiatan. [4].

Desa Tammangalle sebagai desa wisata membutuhkan peta digital untuk media promosi dan informasi. Penelitian ini akan merancang sistem informasi peta digital desa Tammangalle menggunakan google maps dan geodatabase untuk menyimpan data koordinat hasil yang direncanakan sebuah sistem berbasis web berupa peta digital yang menyajikan informasi mengenai wilayah administratif desa tammangalle dan objek wisata.

\section{TINJAUAN PUSTAKA}

\subsection{Sistem Informasi Geografis}

Salah satu jenis informasi yang berhubungan dengan data spasial (keruangan) yang mengenai daerah - daerah yang terdapat di permukaan bumi adalah sistem informasi geografi (SIG). Deskripsi dari SIG adalah suatu sistem informasi khusus yang mengelola data yang memiliki informasi spasial atau dalam arti yang lebih sempit, adalah suatu sistem komputer yang memiliki kemampuan untuk membangun, menyimpan, mengelola dan menampilkan informasi yang bereferensi geografis, misalnya data yang diidentifikasikan menurut lokasinya, dalam sebuah database. Pada kenyataannya SIG merupakan bagian dari ilmu Geografi Teknik (Technical Geography) berbasis computer yang digunakan untuk menyimpan dan memanipulasi data - data spasial (keruangan) untuk kebutuhan atau kepentingan tertentu [5]. SIG sudah digunakan secara luas untuk mengakses informasi tentang suatu lokasi [6]. Keputusan yang diambil khususnya yang berkaitan dengan aspek keruangan/spasial [7].

\subsection{Sistem Peta Digital}

Peta digital adalah representasi fenomena geografik yang disimpan untuk ditampilkan dan dianalisis oleh komputer digital [8]. Setiap objek pada peta digital disimpan sebagai sebuah atau sekumpulan koordinat [9].
Sebagai contoh, objek berupa lokasi sebuah titik akan disimpan sebagai sebuah koordinat, sedangkan objek berupa wilayah akan disimpan sebagai sekumpulan koordinat. Beberapa kelebihan penggunaan peta digital dibandingkan dengan peta analog (yang disimpan dalam bentuk kertas atau media cetakan lain), antara lain dalam hal [8]:

1. Peta digital kualitasnya tetap. Tidak seperti kertas yang dapat terlipat, memuai atau sobek ketika disimpan, peta digital dapat dikembalikan ke bentuk asalnya kapanpun tanpa ada penurunan kualitas.

2. Peta digital mudah disimpan dan dipindahkan dari satu media penyimpanan yang satu ke media penyimpanan yang lain. Peta analog yang disimpan dalam bentuk gulungan-gulungan kertas misalnya, memerlukan ruangan yang lebih besar dibanding dengan jika peta tersebut disimpan sebagai peta digital dalam sebuah hard disk, CD-ROM atau DVD-ROM.

3. Peta digital lebih mudah diperbarui. Penyuntingan untuk keperluan pemutakhiran data atau perubahan sistem koordinat misalnya, dapat lebih mudah dilakukan menggunakan perangkat lunak tertentu.

Secara teori, pemetaan digital merupakan proses kompilasi data dalam bentuk gambar digital. Fungsi utamanya adalah untuk menghasilkan peta yang memberikan representasi akurat dari daerah tertentu. Peta digital awalnya memeiliki fungsi dasar yang sama seperti peta analog, mereka memberikan pandangan virtual dari jalan umum digariskan oleh medan yang meliputi daerah sekitarnya. Peta digital dapat digunakan untuk berbagai kebutuhan seperti informasi pemetaan aliran listrik [10], mencari tempat menarik dan layanan lokasi telah ditambahkan untuk membuat peta digital lebih sadar pengguna [11].

\subsection{Maps API}

Google Maps adalah layanan pemetaan web gratis oleh google yang menyediakan berbagai jenis informasi geografis. Google maps memungkinkan seseorang untuk mencari tempat atau dapatkan petunjuk arah dari satu tempat ke tempat lain [12] selain itu juga dapat Melihat dan menavigasi gambar-gambar tingkat panorama horizontal dan vertikal dari berbagai kota di seluruh dunia. Pengguna juga dapat memanfaatkan google maps untuk memperoleh informasi spesifik seperti lalu lintas, lokasi wisata pada titik tertentu [13], digunakan untuk perencaan aliran listrik PLN [10], serta dapat melihat potensi suatua wilayah [14]. Google Maps menyediakan API yang dapat digunakan untuk menyesuaikan peta dan informasi yang akan ditampilkan. Google Maps menyediakan empat jenis peta. Antara lain:

- ROADMAP - Ini adalah tipe default. Jika Anda belum memilih jenisnya, ini akan ditampilkan. Ini menunjukkan tampilan jalan dari wilayah yang dipilih.

- SATELIT - Ini adalah jenis peta yang menunjukkan citra satelit dari wilayah yang dipilih.

- HYBRID - Jenis peta ini menunjukkan jalan utama pada citra satelit.

- TERRAIN - Ini adalah tipe peta yang menunjukkan medan dan vegetasi 


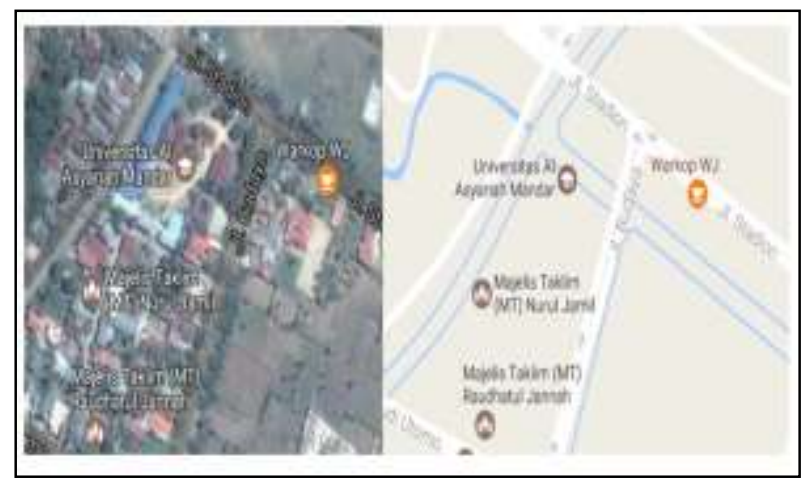

Gambar 2.1. Jenis Peta pada Google Maps

Peta dapat dimodifikasi menggunakan Google Map API yang terdiri dari blok kode, API singkatan dari Application Program Interface adalah satu set dari Rutinitas, protokol, yang menentukan bagaimana beberapa perangkat lunak Komponen harus berinteraksi satu sama lain. Google menyediakan Gambar satelit, peta jalan, peta terestrial, dan geocoding. Karena ini berbasis web maka sistem informasi geografis dengan Google Map adalah sumber dan pilihan yang baik bagi pengguna [2].

\section{METODE PENELITIAN}

\subsection{Persiapan Data}

Data Penelitian diperoleh dari sumber-sumber yang berbeda, termasuk melakukan orientasi medan untuk melihat vegetasi yang ada di desa Tammangalle, melakukan interview langsung dilapangan, serta mengumpulkan data sekunder dari kantor desa Tammangalle. Data ini kemudian digunakan sebagai pedoman untuk menemukan dan mengetahui lokasi dilapangan. tahap persiapan data dilakukan, pertama data lokasi dan vegetasi yang ada di desa, kedua, titik lokasi vegetasi di peta ini dilakukan untuk mendapatkan koordinat lokasi baik dalam Lintang Selatan maupun Bujur Timur (LS-BT). Pada web sistem informasi peta digital yang dibuat ini akan dimudahkan dengan cara melihat peta kemudian melakukan klik pada lokasi vegetasi dalam peta kemudian keterangan lokasi akan secara otomatis muncul dalam form yang telah disediakan dan tersimpan dalam database. Ketiga, menghubungkan antara data spasial (koordinat peta) dengan data atribut sebagai informasi yang memberikan keterangan mengenai peta atau lokasi pada peta. Data ini akan dibangun menggunakan $M y S Q L$.

\section{Gambar Satelit Desa Tammangalle}

Gambar satelite di diperoleh dengan cara download lokasi desa tammangalle, gambar udara ini sebagai salah satu kebutuhan sistem untuk menggambarkan keadaan sebenarnya posisi dan kondisi wilayah desa Tammangalle. Posisi yang dimaksud adalah pertama, potensi desa yang meliputi pertanian dan perkebunan dan beberapa industri rumahan seperti tenun, tali kapal. kedua, objek wisata yang meliputi wisata alam dan wisata religius. Gambar udara desa Tammangalle disajikan sebagai berikut

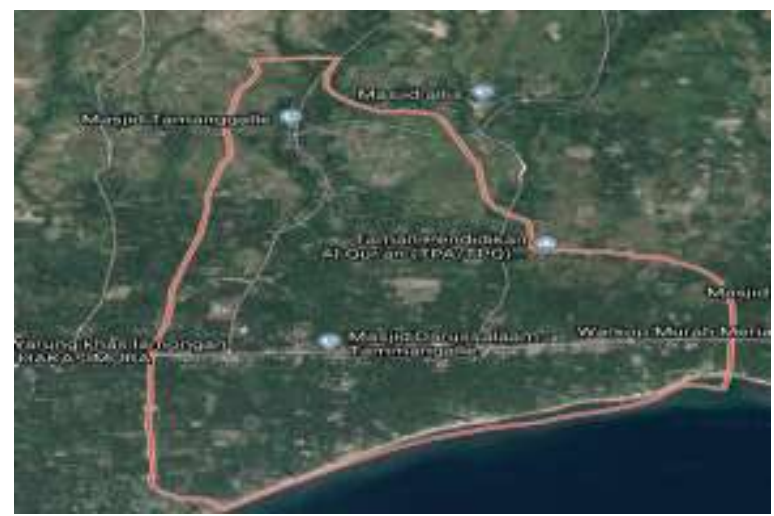

Gambar 3.1 Desa Tamangalle di ambil menggunakan google maps

\section{Data Atribut dan Data Spasial}

Gambar udara Desa Tamanggalle menunjukkan berbagai lokasi yang kemudian diuraikanlah dalam bentuk data atribut dan data spasial sebagai berikut:

Tabel 3.1 Data Atribut dan Data Spasial

\begin{tabular}{l|l|c|c}
\hline $\begin{array}{l}\text { Potensi } \\
\text { Daerah }\end{array}$ & $\begin{array}{l}\text { Lokasi } \\
\text { Daerah }\end{array}$ & BT & LS \\
\hline Perkebunan & $\begin{array}{l}\text { Dusun } \\
\text { panuttungan }\end{array}$ & $119^{0} 03^{\prime} 26^{\prime \prime}$ & $03^{0} 29^{\prime} 48^{\prime \prime}$ \\
\hline Wisata pantai & $\begin{array}{l}\text { Dusun } \\
\text { waitawar }\end{array}$ & $119^{0} 03^{\prime} 32^{\prime \prime}$ & $03^{0} 30^{\prime} 12^{\prime \prime}$ \\
\hline $\begin{array}{l}\text { usaha } \\
\text { minyak } \\
\text { kelapa }\end{array}$ & $\begin{array}{l}\text { Dusun } \\
\text { tammangalle }\end{array}$ & $119^{0} 02^{\prime} 58^{\prime \prime}$ & $03^{0} 30^{\prime} 10^{\prime \prime}$ \\
\hline $\begin{array}{l}\text { Wisata } \\
\text { kerajinan } \\
\text { (tenun) }\end{array}$ & $\begin{array}{l}\text { Dusun } \\
\text { tammangalle }\end{array}$ & $119^{0} 03^{\prime} 14^{\prime \prime}$ & $03^{0} 30^{\prime} 18^{\prime \prime}$ \\
\hline $\begin{array}{l}\text { Wisata } \\
\text { religius }\end{array}$ & $\begin{array}{l}\text { Dusun } \\
\text { panuttungan }\end{array}$ & $119^{0} 03^{\prime} 20^{\prime \prime}$ & $03^{0} 29^{\prime} 30^{\prime \prime}$ \\
\hline
\end{tabular}

Sumber Data: Google Maps dan Profil Desa Tammangalle

Selain dari data atribut dan data spasial di atas maka ada pula data tentang wilayah administratif desa diantaranya nama-nama dusun di desa Tammangalle ada 3 yaitu sebagai berikut :

1. Dusun Tammangalle

2. Dusun Waitawar

3. Dusun Panuttungan

Adapun batas-batas wilayahnya sebagai berikut :

1. Utara berbatasan dengan desa Mosso dan desa Pallis

2. Selatan berbatasan dengan Teluk Mandar

3. Barat berbatasan dengan kelurahan Balanipa

4. Timur berbatasan dengan desa Galung Tulu

Pada dasarnya ada sistem informasi yang dibuat ini hanya dapat dikelola oleh satu level administrator 
Universitas AL Asyariah Mandar

sedangkan pengunjung hanya dapat melihat informasi.

Kerangka sistem dapat dilihat pada gambar 3.2.

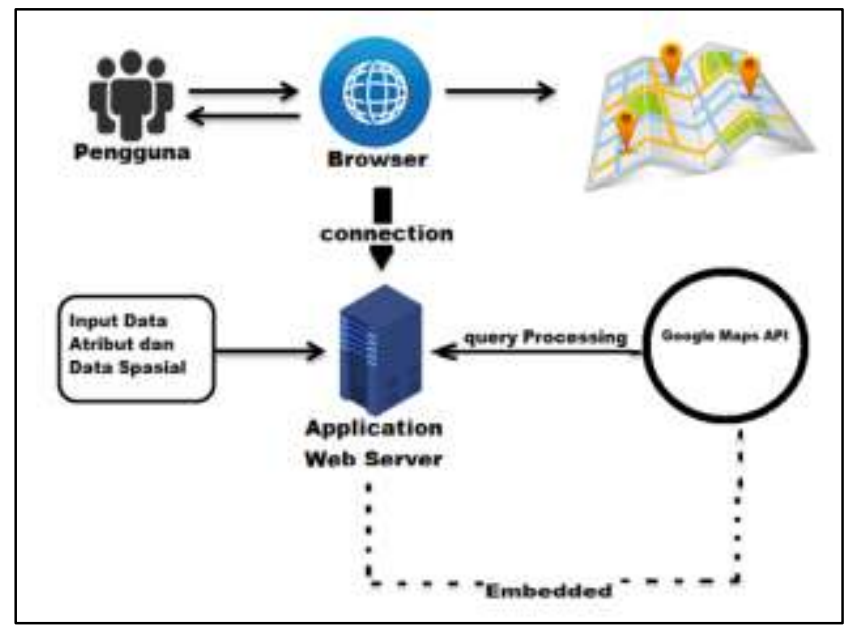

Gambar 3.1 Kerangka Sistem

Tabel 3.3 Penjelasan Kerangka Sistem

\begin{tabular}{|c|c|c|}
\hline Input & Proses & Output \\
\hline $\begin{array}{l}\text { Input pada sistem } \\
\text { ini terdapat dua } \\
\text { macam data } \\
\text { 1. Data atribut } \\
\text { 2. Data spasial }\end{array}$ & $\begin{array}{l}\text { Data tersimpan } \\
\text { didalam } \\
\text { database } \\
\text { kemudian } \\
\text { ditampilkan pada } \\
\text { peta digital } \\
\text { berbasis web. } \\
\text { Pada bagian ini } \\
\text { digunakan tehnik } \\
\text { query untuk } \\
\text { memasukkan } \\
\text { API google maps }\end{array}$ & $\begin{array}{l}\text { Dilihat oleh } \\
\text { user tentang } \\
\text { potensi desa } \\
\text { tersebut pada } \\
\text { peta digital }\end{array}$ \\
\hline
\end{tabular}

Sistem yang dibangun memiliki administrator sistem yang menginput data informasi desa dan data atribut kedalam database server, sementara itu google maps API Key di embedded kedalam administrator web sistem dan data spasial dari google maps dimasukkan kedalam data base hasil query processing akan menampilkan peta beserta data informasi administratif Desa Tammangalle.

\section{Singkronisasi google maps API}

Selanjutnya akan dikoneksikan google maps, agar ini bekerja dengan baik maka dilakukan proses embedded google API key kedalam pemrograman. Script file dapat dilihat dikotak berikut.

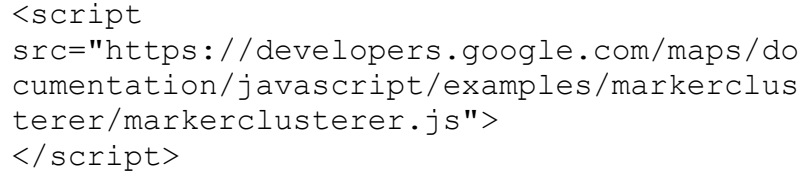

$<$ script

src="https://maps.googleapis.com/maps/api/ js?key=AIzaSyB91 HezlDNeDYSehnCa2oQoKG_bIBu

b198\&callback=initMap" $></$ script $>$

Ketika pengguna terhubungan dengan halaman peta maka permintaan akan dikirm ke google maps dan google akan menampilkan peta sesuai data spatial yang terdapat dalam database MySQL sementara informasi atributnya disajikan ketika pengguna melakukan klik pada area yang telah dibuat.

\section{4..HASIL PENELITIAN \\ 4.1 Pembuataan Peta}

Sebuah sistem informasi peta digital desa Tammangalle yang disingkronkan dengan google maps API untuk melakukan visualisasi data tentang wilayah administratif desa Tammangalle dan vegetasi yang ada. Sistem informasi peta digital berbasis web dibangun menggunakan perangkat lunak adobe dreamweaver untuk membuat halaman HTML, PHP, CSS dan Javascript sementara API Key di embedded kedalam sistmem. Pada dasarnya ada dua jenis arsitektur yang dibangun pada web GIS application yakni sisi pengguna (end user) dan sisi administrator.

\subsubsection{Pembuatan Peta Desa}

Untuk mendesain peta wilayah adminitrasi beserta data atribut dilakukan oleh adminitrator dengan membuat desain didalam sistem informasi peta digital dengan melakukan klik menu "info desa" lalu klik "identitas desa" dan kemudian klik di tombol "peta wilayah desa" dan sistem akan menampilkan form desain yang terhubung dengan google map. Untuk lebih detailnya perhatikan gambar dibawah.

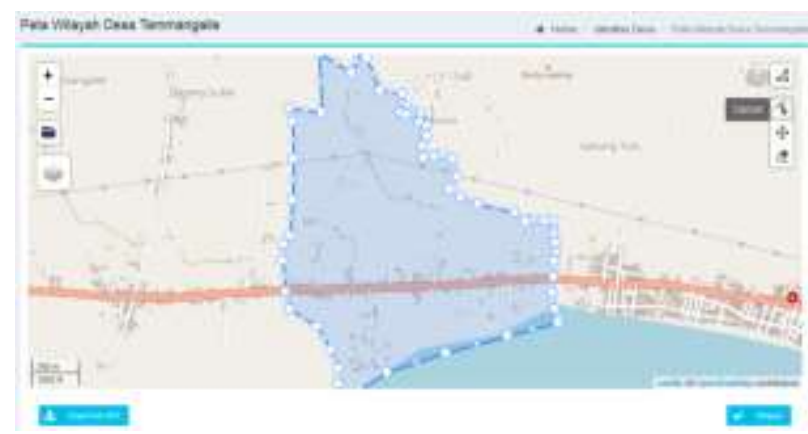

Gambar 4.1. Pembuatan/Desain Peta

Berikut penjelasan tentang cara pembuatan peta desa yaitu sebagai berikut, pada halaman edit desa menyediakan beberapa tool yang terdapat di sebelah kanan paling atas yakni

1) Draw polygons yang berfungsi untuk membuat area wilayah desa dengan cara menarik setiap sudut dan batas-batas desa sesuai dengan peta desa tammangalle dan juga memanfaatkan google maps sebagai panduan dalam pembuatan peta yang tampil bersamaan dalam halaman desin peta tersebut. 
Universitas AL Asyariah Mandar

2) Fitur yang kedua adalah edit layers fitur ini berfungsi untuk mengedit area atau wilayah yakni pada batas dan setiap sudutnya agar lebih detail dan mendekati peta aslinya yang telah dibuat sebelumnya dengan draw polygons.

3) Fitur yang ketiga adalah drag layers, fitur ini berfungsi untuk memindahkan area peta yang telah dibuat agar sesuai dengan vegetasi desa Tammangalle yang terdapat pada peta google maps yang ada di dalam sistem.

4) Remove layers yaitu fitur yang difungsikan untuk menghapus area peta yang telah dibuat fitur ini digunakan biasanya saat admin mendesain dengan draw polygons suatu peta dan terjadi kesalahan pada area peta yang telah dibuat maka dapat menggunakan fitur tersebut untuk menghapus kesalahan.

\subsubsection{Pembuatan Peta Dusun}

Untuk pembuatan peta dusun ini terdapat di menu "info desa" lalu kemudian pilih "wilayah administratif" dan klik tombol peta dibagian aksi pada dusun yang akan didesain.

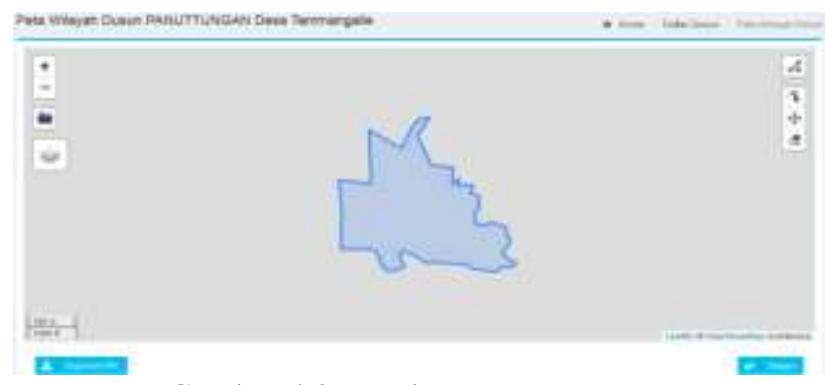

Gambar 4.2. Pembuatan Peta Dusun

Kesulitan dalam membuat peta wilayah dusun dinilai lebih rumit dibandingkan dengan pembuatan wilayah desa. Dimana pembuat peta akan membuat dua jenis tampilan di browser yakni halaman admin di bagian menu wilayah administratif dan halaman menu pemetaan guna untuk memastikan garis dari setiap dusun sejajar dengan garis wilayah desa, tahapan pembuatannya sebagai berikut

1) Menggunakan draw polygons dengan membuat wilayah dusun terlebih dahulu di halaman menu "wilayah administratif" dengan patokan pada peta asli wilayah dusun tammangalle setelah itu pembuat akan masuk tampilan browser lain yakni menu "pemetaan" untuk mensejajarkan setiap sudut dari peta dusun dan desa agar garisnya sejajar.

2) Dan jika belum sejajar maka fitur yang lain digunakan yakni edit layers dengan cara menarik setiap sudut peta dan membuatnya sejajar satu sama lain. Dan fitur yang lain seperti drag layers dan remove layers digunakan jika diperlukan utamanya dalam mengembalikan kesalahan yang terjadi.

\subsection{Sistem Informasi Peta Digital Desa Tammangalle}

Pada Sistem Informasi peta digital desa tammangalle ini menyediakan fitur bagi pengguna di bagian awal tampilan yakni beranda menampilkan informasi berupa identitas desa tammangalle, menu wilayah administratif, menampilkan berbagai wilayah administratif di desa tammangalle seperti dusun-dusun, serta mempermudah pengunjung menuju suatu lokasi desa tammangalle yang ada di kabupaten polewali mandar.

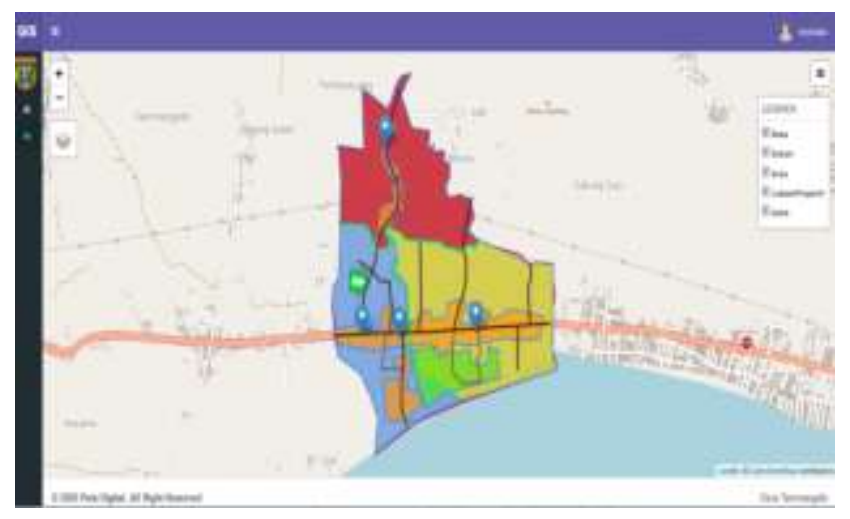

Gambar 4.1 Halaman Pengunjung web

\section{KESIMPULAN}

Peta digital dirancang untuk lebih mempermudah dalam menemukan informasi tentang wilayah administratif dan objek wisata Desa Tammangalle dan untuk penelitian selanjutnya kiranya sistem ini dapat menjadi bahan referensi baru bagi penelitian berlanjut. Selain itu peta digital dapat digunakan sebagai bahan dan pedoman dalam pembangunan infrastruktur dan ekonomi desa, dengan adanya peta digital yang dirancang ini dapat menjadi rekomendasi kepada pemerintah untuk digunakan sebagai media interaktive yang membantu pengunjung dalam menenmukan informasi seputar Tammangalle.

\section{Daftar Pustaka}

[1] S. Kurniawan, H, 2009, Aplikasi Peta Digital Universitas Muhammadiyah Surakarta, Tugas Akhir, Fakultas Teknik Jurusan Teknik Elektro Universitas Muhammadiyah Surakarta.

[2] Chassiakos, A.P.dan, Sakellaropoulos, S.P 2008, A web-based system for managing construction information. Advances in Engineering Software (39) 865-876.

[3] Qashlim, A, 2014, Web Aplikasi Dashboard untuk Evaluasi Human Computer Interaction dan Usability, JTRISTE, Vol.1, No.2, 2355-3677, 39 49

[4] Athanasiadis, A. dan Andreopoulou, Z. 2013, A web Information System application on Forest Legislation: The case of Greek Forest Principles. Procedia Technology ( 8 ) 292-299.

[5] Colin Childs, 2009, The Top Nine Reasons to Use a File Geodatabase, ESRI Education Services 
Universitas AL Asyariah Mandar

[6] Mulyanto Darmawan, Sistem informasi Geografi (SIG) dan Standarisasi Pemetaan Tematik Pusat Survei Sumberdaya Alam Darat, Badan Koordinasi Survei dan Pemetaan Nasional (BAKOSURTANAL).

[7] Deny Wiria Nugraha, 2012, Perancangan sistem informasi geografis Menggunakan Peta Digital, tugas akhir, Jurusan Teknik Elektro, Fakultas Teknik, Universitas Tadulako.

[8] Jamalul Lail, Arief Ridho Kusuma, 2015, Peta Digital Dusun Sentono, tugas akhir Jurusan Analis Kimia, Fakultas Matematika dan Ilmu Pengetahuan Alam, dan Jurusan Arsitektur, Fakultas Teknik Sipil dan Perencanaan Universitas Islam Indonesia.

[9] Ruut Austin, 2016, Sistem Informasi Geografis Pemetaan Pelayanan Umum Di Palembang Berbasis Android, tugas akhir, program studi Sistem Informasi fakultas dakwah dan komonikasi, Universitas Negeri Islam Raden Fatah Palembang.

[10] Muhammad Afandi, Arief Susanto, Anastasya Latubessy, 2014, Sistem Informasi Geografis Pendataan Dan Pengarsipan Aset PT. PLN (PERSERO) Distribusi Jateng dan D.I.Y, tugas akhir, Program Studi Teknik Informatika, Fakultas Teknik, Universitas Muria Kudus Gondangmanis, PO Box 53, Bae, Kudus 59352

[11] Fedro Antonius Pardede, Spits Warnars H.L.H, Pemanfaatan teknologi sistem informasi geografis untuk Menunjang pembangunan daerah, Fakultas Teknologi Informasi, Universitas Budi Luhur.I

[12] Hamka, Akhmad Qashlim, Syarli, Sistem Informasi Geografis Kawasan Bencana Alam Kabupaten Polewali Mandar dengan Google Maps Program Studi Sistem Informasi, Program Studi Teknik Informatika.

[13] Narah Nurindra, Affandy, M.Kom, Ph.D., Pengembangan Sistem Informasi Geografis Objek Wisata Di Kota Yogyakarta Berbasis Web, tugas akhir, Jurusan Sistem Informasi, Fakultas Ilmu Komputer, Universitas Dian Nuswantoro.

[14] Rastuti, Leon Andretti Abdillah, Eka Puji Agustini, 2015, Sistem Informasi Geografis Potensi Wilayah Kabupaten Banyuasin Berbasis Web, tugas akhir, Program Studi Sistem Informasi, Fakultas Ilmu Komputer, Universitas Bina Darma Palembang, Indonesia 